\title{
The biology and the genetics of Hürthle cell tumors of the thyroid
}

\author{
Valdemar Máximo1,2, Jorge Lima1,2, Hugo Prazeres1,3, Paula Soares ${ }^{1,2}$ and \\ Manuel Sobrinho-Simões ${ }^{1,2,4}$ \\ IInstitute of Pathology and Immunology of the University of Porto (IPATIMUP), Porto, Portugal \\ 2Department of Pathology, Medical Faculty of the University of Porto, Porto, Portugal \\ 3Portugese Institute of Oncology, Coimbra Centre (IPOFG, EPE), Coimbra, Portugal \\ ${ }^{4}$ Department of Pathology, Hospital S. João, Porto, Portugal
}

Correspondence should be addressed

to P Soares

Email

psoares@ipatimup.pt

The authors and journal apologise for an omission in the above paper, which appeared in volume 19 part 4, pages R131-R147. The text "This work was also supported by FEDER funds through Programa Operacional Factores de Competitividade - COMPETE (FCOMP-01-0124-FEDER 011267)" was omitted from the Funding section given on page R142.

The correct Funding section is given in full below:

\section{Funding}

This work was partially supported by the Portuguese Science and Technology Foundation (FCT) through the grant SFRH/BPD/72004/2010 (H Prazeres), through the Programs Ciência 2007 (V Máximo) and Ciência 2008 (J Lima) and through the project (PIC/IC/83037/2007). IPATIMUP is an Associate Laboratory of the Portuguese Ministry of Science, Technology and Higher Education and is partially supported by the FCT. This work was also supported by FEDER funds through Programa Operacional Factores de Competitividade - COMPETE (FCOMP-01-0124-FEDER 011267). 